This article was published in AIChE Journal, 62(8), 2794-2802, 2016

http://dx.doi.org/10.1002/aic.15262

\title{
Intensification of Photocatalytic Pollutant Abatement in Microchannel Reactor Using $\mathrm{TiO}_{2}$ and $\mathrm{TiO}_{2}$-Graphene
}

\section{Natan Padoin}

LEMA - Dept. de Engenharia Química e Engenharia de Alimentos, Universidade Federal de Santa Catarina, Campus Universitario Reitor João David Ferreira Lima, 88040-900 Florianopolis-SC, Brasil

Lu'sa Andrade, Joana Ângelo and Ad’elio Mendes

LEPABE - Faculdade de Engenharia, Universidade do Porto, Rua Dr. Roberto Frias, 4200-465 Porto, Portugal

\section{Regina de F'atima Peralta Muniz Moreira and C'intia Soares}

LEMA - Dept. de Engenharia Qu' imica e Engenharia de Alimentos, Universidade Federal de Santa Catarina, Campus Universitario Reitor João David Ferreira Lima, 88040-900 Florianopolis-SC, Brasil

A microfluidic device was applied to the photocatalytic degradation of methylene blue as a model pollutant. Titanium dioxide nanoparticles (TiO2-P25) and a synthesized composite TiO2graphene catalyst were immobilized on the inner walls of a borosilicate glass microfluidic chip. The deposition evolution of the nanoparticles was evaluated by monitoring the optical profile of the system. It was found that a higher initial reaction rate was obtained in the microreactor containing composite catalyst (TiO2-GR) on the inner walls, but both systems ( $\mathrm{TiO} 2$ and $\mathrm{TiO}_{2}-$ GR) achieved similar reaction rates when the steady-state was reached. Decolorization rate of methylene blue in our microfluidic chips was found to be approximately one order of magnitude higher than equivalent macroscopic systems reported in the literature at similar experimental conditions. Additionally, computational simulations were performed to investigate the physics involved in these processes. The model was experimentally validated for further scale-out studies.

Keywords: microfluidics, photocatalysis, methylene blue, titanium dioxide, graphene, computational modeling

\section{Introduction}

Recently, the application of microchannel technology has attracted great attention due to its potential for the intensification of chemical processes. Microchannel-based devices have been studied in heat and mass transfer operations, such as distillation, absorption and extraction, 1,2 as well as in chemical reaction engineering. ${ }^{3}$ According to Gavriilidis et al., ${ }^{4}$ Jahnisch et al., ${ }^{5}$ Aran et al., ${ }^{6}$ Hartman et al., ${ }^{7}$ and N6el et al., ${ }^{8}$ microreactors are advantageous when compared with reaction vessels with conventional dimensions mainly due to the high surface-to-volume ratio, 
which leads to high heat and mass transfer. Chemical reaction rates are also favored, particularly in heterogeneous reactions in which there is generally the dep- osition of a catalyst film on the inner walls of the device.

Microstructured reactors have a high surface-to-volume ratio. ${ }^{9-11}$ Values in the order of $1 \times 10^{4}$ to $5 \times 10^{4} \mathrm{~m}^{2} / \mathrm{m}^{3}$ can be encountered, while in conventional reactors this ratio varies in the order of $1 \times 10^{2}$ to $1 \times 10^{3}$ (in rare cases) $\mathrm{m}^{2} / \mathrm{m}^{3} .5$ Moreover, when heat transfer is involved, coefficients in the order of $10 \mathrm{~kW} / \mathrm{m}^{2} / \mathrm{K}$ are encountered in microchannels (a value significantly superior to those obtained in traditional equipment), since this parameter is inversely proportional to the channel diameter. ${ }^{5}$ Thus, it is possible to rapidly remove or insert heat in a way that the chemical reactions may be conducted in perfect isothermal conditions and with precisely defined residence times, which consequently enhances the selectivity, yield and quality of the products. 5

Although the chemical reaction kinetics is independent of the scale in which the process is carried out, the transport phenomena are not, opening the opportunity for process optimization in microstructured devices. ${ }^{4}$ According to Hartman et al., ${ }^{7}$ the performance of mass transfer limited reactions is improved by two orders of magnitude in microreactors. Furthermore, microfluidic devices allow precise process control, require small space and generate low quantity of waste. Matsushita et al. ${ }^{12}$ also pointed out that microreactors exhibit short molecular diffusion path, fast mixing and are usually operated under laminar flow conditions.

When applied to photocatalytic processes, microreactors are advantageous due to the short irradiation path, which reduces the photon transport resistance, ${ }^{8}$ commonly encountered in processes carried out in conventional reactors with catalyst immobilized on the inner walls, ${ }^{6}$ and allow spatial homogeneity of irradiance. ${ }^{9-12}$ In fact, extensive research has been reported on the application of microchannel reactors in photo- catalytic processes. ${ }^{10-15}$

However, few contributions are concerned about the use of this technology for the mitigation of environmental problems. ${ }^{16-21}$ Furthermore, the effect of the operational conditions and geometry of the microchannels were not yet completely elucidated. It has been reported that the degradation of organic compounds depends on the dimensions of the microchannel ${ }^{10}$ and the profiles of velocity and concentration of the pollutant. ${ }^{16,18}$ In some instances, mass transfer limitations on the overall rate of pollutant degradation are observed. ${ }^{22}$ Additionally, even low cost materials can be used ${ }^{23}$ for photodegradation of a variety of compounds, such as indigo carmine, diclofenac and benzoylecgonine ${ }^{24}$, and photoinactivation of virus. ${ }^{24}$ When compared with traditional batch vessels, microstructured reactors can reach reaction rates one order of magnitude higher. ${ }^{23}$

Deep investigation about the fluid dynamics and the transport phenomena (especially mass transfer) is needed for enhanced design of photomicroreactors and for the application of this technology in large scale operations. ${ }^{9}$ According to $\mathrm{Su}$ et al., ${ }^{9}$ fundamental modeling aspects like the radiation distribution in microchannels, an essential parameter for integrating light source and reactor designs for process optimization, have not been published so far and are, thus, worthy of studying. Once rigorous models are available, the performance of micro- fluidic devices applied to photocatalytic pollutant abatement can be assessed and enhanced, and challenging scale-out strategies, such as the internal numbering-up, ${ }^{9}$ can be better explored.

In this work, a microfluidic device was investigated aiming its application for photocatalytic degradation of pollutants in water treatment processes. Titanium dioxide nanoparticles (TiO - 
Aeroxide ${ }^{\circledR}$ P25 from Evonik ${ }^{\circledR}$ ) and a synthesized graphene-titanium dioxide composite catalyst (TiO2-GR) were immobilized on the inner walls of a borosilicate glass micro- fluidic

chip (Micronit ${ }^{\circledR}$ Microfluidics BV) using a layer-by- layer method. The effect of the operational conditions on the decolorization rate of methylene blue was also investigated. Finally, a rigorous computational model of the photocatalytic process, taking into account light distribution within the device, was implemented and validated by experimental data. This work distinguishes from the published literature in the area of photocatalytic pollutant abatement in microreactors by the investigation of the possibility of using a composite photo- catalyst washcoat, which can be further optimized for sunlight harvesting, and the rigorous computational modeling of the process herein studied, through coupled radiation distribution within the catalyst film and reactive flow based on fundamental physics of semiconductors.

\section{Materials and Methods}

\section{Microfluidic chip, catalysts and immobilization procedure}

Commercial TiO (Aeroxide ${ }^{\circledR}$ P25 from Evonik ${ }^{\circledR}$ ) and a composite catalyst made of TiO2 (P25) and graphene (1\%) were immobilized on the inner walls of two distinct microfluidic chips (Micronit ${ }^{\circledR}$ Microfluidics BV, Enschede, The Netherlands, model R150.676). These chips are assembled with borosilicate glass through powder blasting technique and have an average total volume of $13 \mu \mathrm{L}$, a surface/volume ratio of $\sim 3.5 \times 10^{4}$ $\mathrm{m}^{2} / \mathrm{m}^{3}$ and hydraulic diameter of $\sim 133.5 \mu \mathrm{m}$ ( $\sim 0.78 \mathrm{~m}$ long).

The layer-by-layer immobilization of the TiO2-P25 nano- particles on the inner walls of the microfluidic chip was per-formed by passing a $1 \mathrm{~g} / \mathrm{L}$ aqueous suspension at $\mathrm{pH}$ equal to the point of zero charge of TiO2-P25 ( 7.5) intercalated with thermal treatments. The aqueous suspension was vigorously mixed, collected with a micropipette and injected in a port of the microdevice until it filled the channel. After removing the excess solution, the microfluidic chip was placed in a blow dryer (Hotwind System, Leister ${ }^{\circledR}$, Switzerland) and submitted to thermal treatment ( $25^{\circ} \mathrm{C}$ to $450^{\circ} \mathrm{C}$ in $\sim 4 \mathrm{~min}, 450^{\circ} \mathrm{C}$ for $5 \mathrm{~min}$ and $450^{\circ} \mathrm{C}$ to $30^{\circ} \mathrm{C}$ in $\sim 7 \mathrm{~min}$ ). At the end of the thermal cycle, the microdevice was removed from the heating equipment and allowed to equilibrate with the room temperature. This procedure was repeated cyclically. Between cycles the microchip was submitted to optical analysis in a UV-VIS-NIR spectrophotometer (UV-3600, Shimadzu ${ }^{\circledR}$, Japan). The transmittance ( $T$ ) was obtained in the wavelength range of $\lambda=200-800 \mathrm{~nm}$.

The TiO2-graphene composite catalyst was synthesized using the hydrothermal method proposed by Zhang and co- workers. ${ }^{22}$ Graphene oxide was prepared from graphene nanoplatelets by oxidation with $\mathrm{KMnO} 4$ in sulfuric acid-modified Hummer's method. ${ }^{25}$ The detailed description of the composite preparation is given elsewhere. ${ }^{26}$

A similar approach used for immobilization of the titanium dioxide nanoparticles (P25) was applied for supporting the composite P25-graphene photocatalyst on the inner walls of the microreactor. A $1 \mathrm{~g} / \mathrm{L}$ dispersion of the compound was pre- pared using distilled water and then sonicated for $30 \mathrm{~min}$. The solution was then collected with a micropipette and injected in a port of the microdevice until it filled the channel. The device was then submitted to the thermal treatment previously described. However, in this case the thermal ramp consisted in heating from room temperature to $150^{\circ} \mathrm{C}$, which was held for $30 \mathrm{~min}$ allowing for complete solvent evaporation. The device was then removed from the heating equipment and allowed to equilibrate with the room temperature. Among the immobilization cycles of TiO2-GR, optical analysis were performed in the same manner previously described. 
SEM images $\left(\mathrm{JEOL}^{\circledR}{ }^{\circledR} \mathrm{JSM}-6390 \mathrm{LV}\right)$ were acquired from a microchannel containing TiO2 nanoparticles before the conduction of chemical reactions (with accelerating voltage of $10 \mathrm{kV}$ and magnifications of $65 \mathrm{x}$ and 500x).

\section{Kinetics of methylene blue decolorization}

The performance of the microfluidic device for environmental applications to degrade methylene blue dye $(\mathrm{C} 16 \mathrm{H} 18 \mathrm{ClN} 3 \mathrm{~S} .3 \mathrm{H} 2 \mathrm{O})$ was evaluated, because photocatalytic decolorization has been extensively studied in several reactor configurations. ${ }^{27-29}$ A stock solution of methylene blue (Sigma ${ }^{\circledR}$ ) was used to prepare aqueous solutions with concentrations of 1 and $10 \mathrm{mg} / \mathrm{L}$.

To allow fluid flow through the microchannels, 1/32" bonded-port Ultem ${ }^{\circledR}$ connectors from Labsmith $^{\circledR} \quad$ (Livermore CA), supplied by Mengel Engineering (Virum, Denmark), were carefully glued on each port of the microreactor. One- piece PEEK fittings allowed leak-free interface between the port connectors to 1/32" OD, $250 \mu \mathrm{m}$ ID PEEK tubing. A PEEK one-piece plug was attached to one of the port connectors allowing a single-inlet/single-outlet setup.

The PEEK tubing was connected to flexible tubing (PharMed ${ }^{\circledR}$ BPT NSF-51) attached to a peristaltic pump (Ismatec ${ }^{\circledR}, \operatorname{IDEX}^{\circledR}$ Health \& Science GmbH, Germany) to control the continuous fluid flow from the pollutant solution reservoir through the microfluidic chip. In particular, a mean residence time of $\tau=8.6 \mathrm{~s}$ was adopted in the experiments. At the other side of the microreactor, PEEK tubing was used to collect samples in glass vials, which were submitted to further spectroscopic analysis (UV-VIS-NIR spectrophotometer UV- 3600, Shimadzu ${ }^{\circledR}$, Japan) at the range of $\lambda=400-800 \mathrm{~nm}$. The concentration of methylene blue at the end of the system was evaluated by spectrophotometric method at $\lambda=665 \mathrm{~nm}$. UV-A lamps (highest emission at $\lambda=365 \mathrm{~nm}$, two $6 \mathrm{~W}$ black-light-blue bulbs, model VL-206-BL, Vilbert Lourmat, France) were used as photon source for the kinetics experiments, positioned at a distance of $15 \mathrm{~cm}$ above the microreactor. Light irradiance was measured at the surface of the microchip by radiometry (UV radiometer HD 2102.2, Delta/ OHM, Italy) and the value of $6 \mathrm{~W} / \mathrm{m}^{2}$ was encountered. Minimum light dispersion in the experimental assays was ensured. Moreover, stray light incidence on the experimental setup was blocked involving it with a black barrier.

Initially, the methylene blue solution was allowed to flow through the microchannel under dark conditions for the investigation of adsorption effect of dye molecules on the photocatalyst surface during the process. The solution was pumped through the device for $50 \mathrm{~min}$. Thereafter, two samples were continuously collected in intervals of $40 \mathrm{~min}$. This time interval was adopted for all sample collections since it yielded the volume required for the spectrophotometric analysis.

Based on the procedure adopted, all kinetic runs were carried out as follows: (1) the methylene blue solution was pumped through the microreactor for 50 min under dark conditions; (2) then, an initial sample was collected for 40 min also under dark conditions; (3) the light was turned on; (4) samples were collected in time intervals of $40 \mathrm{~min}$; and (5) all samples were analyzed by spectrophotometry (absorbance measured at the wavelength of $\lambda=665 \mathrm{~nm}$ ).

Additionally, an investigation of the influence of photolysis on the process was carried out. For that, the procedure above described was applied to a microfluidic chip with the same characteristics previously mentioned, but without any catalyst immobilized on its inner walls. The initial (under dark) and probe (under light) solutions were also analyzed in spectrophotometer at the wavelength of $665 \mathrm{~nm}$. Figure 1 illustrates a scheme of the system adopted in the kinetic studies. 


\section{Computational modeling}

Numerical simulations were conducted with the CAE tool COMSOL ${ }^{\circledR}$ Multiphysics (COMSOL, Boston), version 4.3a. In particular, conditions similar to the experiments ( $C 0=1 \mathrm{mg} / \mathrm{L}$ and $\tau=8.6 \mathrm{~s}$ ) were evaluated. Accordingly, a three-dimensional (3-D) model reproducing all features of the microfluidic chip used in the experiments was developed. The solution was supplied at one of the inlet ports with uniform velocity $(u=0.108 \mathrm{~m} / \mathrm{s})$. At the extreme opposite of the channel null gauge pressure was assigned $(p=0 \mathrm{~Pa})$. All other faces were impermeable to fluid flow and no-slip boundary condition was applied. The velocity and pressure fields inside the device was solved through Navier-Stokes equations (Eq. 1), coupled with the mass conservation equation (Eq. 2):

$$
\begin{gathered}
\rho(\mathbf{u} \cdot \nabla) \mathbf{u}=\nabla \cdot\left[-p \mathbf{I}+\mu\left(\nabla \mathbf{u}+(\nabla \mathbf{u})^{T^{\prime}}\right)\right]+\mathbf{F} \\
\rho \nabla \cdot \mathbf{u}=0
\end{gathered}
$$

where $\rho\left(\mathrm{kg} / \mathrm{m}^{3}\right)$ is the density, $u(\mathrm{~m} / \mathrm{s})$ is the velocity, $t(\mathrm{~s})$ is time, $p(\mathrm{~Pa})$ is the pressure, $I$ (dimensionless) is the identity matrix, $\boldsymbol{\mu}(\mathrm{kg} / \mathrm{m} / \mathrm{s})$ is the dynamic viscosity, $T^{\prime}$ 'is the transpose operator and $F\left(\mathrm{~N} / \mathrm{m}^{3}\right)$ represent generic body forces. Steady-state, laminar and incompressible fluid conditions were assumed.

Moreover, the reactive transport of methylene blue molecules within the microchannel was modeled through the convection-diffusion equation expressed by Eq. 3:

$$
\nabla \cdot\left(-D_{i} \nabla C_{i}\right)+\mathbf{u} \cdot \nabla C_{i}=R_{i}
$$

where $D i \quad\left(\mathrm{~m}^{2} / \mathrm{s}\right)$ is the species diffusion coefficient, $C i\left(\mathrm{~mol} / \mathrm{m}^{3}\right)$ is the species concentration and $R i\left(\mathrm{~mol} / \mathrm{m}^{3} / \mathrm{s}\right)$ is the species reaction rate. It is interesting to notice that the species transport model is coupled with the fluid flow model through the velocity field $(u)$. In particular, the photocatalytic reaction rate was modeled as a boundary condition at the microchannel walls (i.e., the volumetric reaction rate $R i$ was neglected), expressed through the rate presented in Eq. $4::^{30}$

$$
-r=k_{i} C_{i}\left(\frac{\alpha I_{0}}{B p_{0} n_{0} \hbar \omega}\right)^{\gamma} \exp (-\gamma \alpha y)
$$

where $k i$ is the pre-exponential factor $\left(\mathrm{s}^{-1}\right), C i\left(\mathrm{~mol} / \mathrm{m}^{3}\right)$ is the species concentration, $\alpha$ $\left(\mathrm{m}^{-1}\right)$ is the optical absorption coefficient, $I 0\left(\mathrm{~W} / \mathrm{m}^{2}\right)$ is the incident UV irradiance, the term BpOno $\left(\approx 3.3 \times 10^{-23} \mathrm{~m}^{3} / \mathrm{s}\right)$ represents the $\mathrm{e}^{-} / \mathrm{h}+$ equilibrium, $\mathrm{h} w$ is the photon energy $\left(5.44 \times 10^{-19} \mathrm{~J}\right.$ for $\mathrm{UV}$ at $\left.365 \mathrm{~nm}\right), \gamma$ (dimensionless) is the electron transfer coefficient and $y$ (m) are Cartesian coordinates.

According to Visan et al. (2014), ${ }^{31}$ the parameter $\gamma$ can be considered equal to the unity for incident irradiance lower than $I O=250 \mathrm{~W} / \mathrm{m}^{2}$. Since the value of $I O$ in the experiments was much lower than this limit $\left(I O=6 \mathrm{~W} / \mathrm{m}^{2}\right)$, we considered $\gamma=1$ in the computational modeling. The optical absorption coefficient $\alpha$ was taken as $6.264 \times 10^{5} \mathrm{~m}^{-1} .32$ Finally, the 
pre-exponential factor $k i$ should be determined. Visan et al. (2014) ${ }^{31}$ obtained the intrinsic kinetic constant $k=40 \mathrm{~s}^{-1}$ for photocatalytic methylene blue degradation under UV irradiation at $365 \mathrm{~nm}$ with $I O=180 \mathrm{~W} / \mathrm{m}^{2}$. The authors found that in this condition the methylene blue degradation rate was approximately independent of the light intensity supplied to the sys- tem. Therefore, one can obtain the kinetic constant considering dependence on light intensity equating an apparent first order kinetic model to the generic expression derived by Nielsen et al. (2012). ${ }^{30}$ Through this procedure we deter- mined the light dependent apparent first-order kinetic constant according to Eq. 5:

$$
k_{i}\left(\frac{\alpha}{B p_{0} n_{0} \hbar \omega}\right)^{\gamma}=k_{a p p, L D}=0.222 \mathrm{~s}^{-1}
$$

Since the value of the photocatalyst film thickness determined experimentally is lower than the cutoff criterion defined by Visan et al. (2014), ${ }^{31}$ a light independent model can be assumed, i.e., there is no necessity to evaluate the light intensity point by point inside the immobilized film and a logarithmic average can be considered, according to Eq. 6:

$$
I_{a v g}=\frac{I_{0}-I_{0} \exp (-\alpha \delta)}{\ln \left(\frac{I_{0}}{I_{0} \exp (-\alpha \delta)}\right)}
$$

Furthermore, the effect of internal mass transfer resistance within the photocatalyst film was accounted through the effectiveness factor $(\eta)$, defined by Eq. 7:

$$
\eta=\frac{3}{\phi^{2}}(\phi \operatorname{coth} \phi-1),
$$

where $\phi$ is the Thiele modulus (dimensionless), expressed for a light dependent first-order reaction as:

$$
\phi=\delta \sqrt{\frac{k_{a p p, L D} I_{0}^{\eta}}{D_{e f f}}},
$$

where $\delta$ is the film thickness (m) and $D \operatorname{eff}\left(\mathrm{m}^{2} / \mathrm{s}\right)$ is the effective diffusion coefficient, taken as $D e f f=D \varepsilon / \tau^{\prime}$. The diffusion coefficient assumed the value $D=4.1 \times 10^{-10} \mathrm{~m}^{2} / \mathrm{s},{ }^{33}$ while the film porosity was defined as $\varepsilon=0.45^{31}$ and the tortuosity as $\tau^{\prime}=3.0 .^{34}$

Therefore, converting the light dependent volumetric apparent first-order constant (kapp, $L D$ ) to a superficial constant, yielding $k^{\prime \prime}$ 'app, $L D=6.25 \times 10^{-6} \mathrm{~m} / \mathrm{s}$, the superficial reaction rate applied to the computational model as a boundary condition was expressed according to Eq. 9:

$$
-r^{\prime \prime}=\eta k^{\prime \prime}{ }_{a p p, I D} I_{0}^{\prime} C_{i}
$$

Complementary simulations in a 2-D domain that represents the cross-section of the 
microchannel accounting the average film thickness was carried out to determine the average light intensity that effectively contributes to the photocatalytic reaction rate at the top, side and bottom layers of the device.

Firstly, the light absorption due to the glass layer positioned on the microchannel was accounted. Thus, considering that $\sim 60 \%$ of the light intensity is attenuated due to the glass contribution (determined by optical analysis in a microchip without any photocatalyst deposited on the inner walls, according to the procedure described in previously, see Figure 2) and taking into account that the incident irradiance on the microfluidic chip surface was $I 0=6.0 \mathrm{~W} / \mathrm{m}^{2}$, one can notice that the effective light intensity that reaches the top photocatalyst layer was $I^{e f f}=3.6 \mathrm{~W} / \mathrm{m}^{2}$. The Beer-Lambert law (Eq. 10) was then applied to calculate the light propagation through the photocatalyst film layers $9,31,35$

$$
\frac{d I}{d y}=-\alpha I
$$

Different average intensities were obtained for the top, side and bottom photocatalyst layers. Therefore, the reaction rate was applied differently to each portion of the microchannel, taking into account the respective average light intensity.

\section{Results and Discussion}

\section{Immobilization of the photocatalysts}

Figure 2a presents the optical profiles obtained during the immobilization procedure for the $\mathrm{TiO} 2$ photocatalyst on the inner walls of the microreactor. The initial curve correspond to the background profiles obtained from the microfluidic chip as acquired (i.e., without any treatment or fluid pumping). The curves tended to a stagnation profile. Specifically for the case of $\mathrm{TiO} 2$ nanoparticles (P25), 16 cycles of immobilization on the microreactor walls were found to be needed for reaching this condition.

Notably, the sharpest variations in the optical profiles were observed in the range $\lambda=300-400$ $\mathrm{nm}$, corresponding to the region where $\mathrm{TiO} 2$ harvests light. These observations are in line with the profiles obtained elsewhere. ${ }^{36}$ Similarly, Figure $2 \mathrm{~b}$ presents the optical profiles obtained during the immobilization procedure for the composite photocatalyst of titanium dioxide and $1 \%$ of graphene (TiO2-GR). Again, a variation mainly in the range $\lambda=300-400 \mathrm{~nm}$ was observed for transmittance profiles. The curves tended to a stagnation profile after only 8 immobilization cycles. This difference in the number of cycles observed for P25 and its composite may be mainly due to the thickness of photocatalyst film deposited in each layer.

The Beer-Lambert law $[I=I 0 \exp (2 \alpha \delta)]$ allowed the estimation of the film thickness in both cases ( $\mathrm{TiO} 2$ and $\mathrm{TiO} 2-\mathrm{GR})$. Considering the absorption coefficient of $\mathrm{TiO}_{2}$ as $\alpha=6.264 \times 10^{5} \mathrm{~m}^{-1}$ at $\lambda=365 \mathrm{~nm}^{32}$ the thickness of the $\mathrm{TiO} 2$ and TiO2-GR immobilized films was estimated as $\delta=1.52 \mathrm{~mm}$. The absorption coefficient of TiO2-GR was assumed equal to $a$ for $\mathrm{TiO} 2$ since graphene is nearly transparent to UV light.

The immobilization procedure adopted in this work, similar to that followed by Choi et al., ${ }^{37}$ represents a different criterion in comparison with the techniques commonly used in related studies in the literature, which generally adopted the mass variation of the microreactor between successive cycles to assess the progress of the deposition. ${ }^{16,19}$ In these works, a surface mass density was defined as cutoff criterion: when this parameter reached a specified value, the deposition process was stopped. This procedure was tested in the present work but without 
success, since there was no significant mass variation between successive cycles, even when evaluating it in a four decimal cases analytical balance.

Figure 3 presents SEM images of cross-sections of the microchannel reactor containing $\mathrm{TiO}_{2}$ nanoparticles immobilized on its inner walls, obtained at the center of the device.

\section{Methylene blue decolorization kinetics}

Under dark conditions, the equilibrium of the adsorption of methylene blue $\left(\sim 0.0272 \mathrm{~g} / \mathrm{m}^{3} / \mathrm{s}\right)$ was achieved after $50 \mathrm{~min}$, as evidenced in Figure 4. The absorption spectra of the samples collected within the intervals of 50-90 min and 90-130 min under dark conditions were similar. Moreover, photolysis had a negligible effect on the process, as evidenced in Figure 5.

Based on these preliminary observations, kinetic runs were carried out to assess the decolorization profiles of methylene blue in the microfluidic chip, aiming to determine the reaction rate. Figure $6 \mathrm{a}$ presents the decolorization profiles obtained from the kinetic experiments using the microreactor containing titanium dioxide nanoparticles (P25) immobilized on its inner walls, while Figure $6 \mathrm{~b}$ shows the decolorization of methylene blue in the microreactor with TiO2-GR immobilized on the walls.

It is possible to observe that a steady-state condition was reached for all cases. A lower initial concentration of the pollutant led to a more pronounced decolorization percentage (i.e., lower values of $C / C 0$ ). For $\tau=8.6 \mathrm{~s}$ and $C O=10 \mathrm{mg} / \mathrm{L}$ the equilibrium was reached at $C / C O$ $=\sim 0.85$ (i.e., ca. $15 \%$ of decolorization was observed). Conversely, for the same value of $s$ and considering $C O=1 \mathrm{mg} / \mathrm{L}$ the steady-state decolorization ratio was $C / C 0=\sim 0.30$ (i.e., ca. $70 \%$ of decolorization). Similarly, Figure $6 \mathrm{~b}$ presents the decolorization profiles for the microreactor containing composite catalyst of titanium dioxide and graphene (TiO2-GR) immobilized on its inner walls. For $\tau=8.6 \mathrm{~s}$ and $C 0=10 \mathrm{mg} / \mathrm{L}$ the equilibrium was reached at $C / C O=\sim 0.80$ (ca. $20 \%$ of decolorization). For $C O=1 \mathrm{mg} / \mathrm{L}$ the steady-state decolorization ratio was $C / C O=\sim 0.20$ (i.e., ca. $80 \%$ of decolorization).

Clearly, it is possible to observe that a higher initial decolorization percentage was observed for the microfluidic chip containing composite catalyst of titanium dioxide and graphene (TiO2-GR) immobilized on its inner walls. However, the equilibrium values obtained at the steady-state for both devices were similar. Thus, it is possible to point out that graphene is influencing the effectivity of the chemical reaction, especially at the early stage. Since the work of Willians, Seger and $\mathrm{Kamar}^{38}$ there is an increasing interest in the use of graphene-based composite semiconductors for photocatalytic processes due to their outstanding properties. According to previous findings, ${ }^{26}$ the enhanced activity of TiO2-GR may be attributed to the decrease in $\mathrm{e}^{-} / \mathrm{h}^{+}$ recombination, since graphene has the ability to accept the electrons photogenerated by P25, as well as the increased adsorption of methylene blue on the graphene sheets. These observations are in line with other works published elsewhere. ${ }^{22,39}$ In fact, the adsorption capacity of graphene sheets is about fourfold higher than pure P25 and twofold higher than P25-GR. ${ }^{26}$ Nguyen-Phan et al. ${ }^{39}$ reported the photodegradation of methylene blue by TiO2-GR composite photocatalysts and also found enhanced performance of this composite when compared with pure $\mathrm{TiO}_{2}$ nanoparticles. Moreover, $\mathrm{Wu}$ et al. ${ }^{40}$ reported enhanced photocatalytic activity when evaluating the decolorization of methylene blue solutions treated with $\mathrm{TiO} 2$ nanocrystals supported on graphene-like bamboo charcoal.

Based on this scenario, the enhanced initial reaction rate of the photocatalytic film of composite TiO2-GR can be explained as follows: due to the high surface area of graphene sheets, the adsorption rate of methylene blue molecules on the surface of the photocatalyst is higher than the reaction rate until a saturation is reached, when the reaction rate equals the adsorption rate. From 
this point on, the reaction rate turns out to be higher than the adsorption rate and is approximately equal to the apparent reaction rate observed in pristine $\mathrm{TiO}_{2}$ nanoparticles. Therefore, methylene blue decolorization proceeds with a rate similar to that achieved with P25, eventually leveling-off to the same equilibrium level obtained with the model photocatalyst. In other words, graphene altered the kinetics of methylene blue decolorization in the microfluidic chip but did not alter the thermodynamic state of the system.

\section{Kinetics modeling}

Assuming that the device can be modeled as a pseudo-PFR reactor, the apparent reaction rate constant can be obtained according to Eq. $11:^{31,41}$

$$
u \frac{d C_{i}}{d x}=-k_{a p p} C_{i},
$$

where $u(\mathrm{~m} / \mathrm{s})$ is the mean velocity at the microchannel (assumed constant), $C i$ is the concentration $(\mathrm{mg} / \mathrm{L}), x(\mathrm{~m})$ are the coordinates along the reactor length and $k a p p\left(\mathrm{~s}^{-1}\right)$ is the volumetric apparent first-order reaction rate constant.

For the microchannel containing $\mathrm{TiO}_{2}$ immobilized on its inner walls operating at $\tau=8.6 \mathrm{~s}$ and $C O=1 \mathrm{mg} / \mathrm{L}$, the apparent reaction rate constant is $k a p p=0.17 \mathrm{~s}^{-1}$. However, for $C O$ $=10 \mathrm{mg} / \mathrm{L} k a p p=0.0226 \mathrm{~s}^{--1}$. Since there was not a linear variation of $k a p p$ when the inlet concentration was increased, the reaction probably follows a Langmuir-HinshelwoodHunge-Watson mechanism. Moreover, when the residence time was decreased to $\tau=5.8 \mathrm{~s}$, the apparent reaction rate assumed the value $k a p p=0.14 \mathrm{~s}^{-1}$ for $C 0=1 \mathrm{mg} / \mathrm{L}$ and $k a p p$ $=0.038 \mathrm{~s}^{-1}$ for $C O=10 \mathrm{mg} / \mathrm{L}$.

Applying the same procedure to the TiO2-GR catalyzed reactions, kapp assumed the values $0.22 \mathrm{~s}^{-1}$ and $0.031 \mathrm{~s}^{-1}$ for $C O=1 \mathrm{mg} / \mathrm{L}$ and $C O=10 \mathrm{mg} / \mathrm{L}$, respectively, maintaining the mean residence time fixed in $\tau=8.6 \mathrm{~s}$.

Therefore, in the microfluidic chip with $\mathrm{TiO} 2$ immobilized on the inner walls submitted to $C 0=10 \mathrm{mg} / \mathrm{L}$ and $\tau=8.6 \mathrm{~s}$, the decolorization rate of methylene blue was $r_{A}=\sim 0.209 \mathrm{~g} / \mathrm{m}^{3} / \mathrm{s}$ at the steady-state. In addition, a reaction rate of $-r A=\sim 0.0988 \mathrm{~g} / \mathrm{m}^{3} / \mathrm{s}$ was observed at the steady- state when carrying out the reaction with $C 0=1 \mathrm{mg} / \mathrm{L}$ and residence time of $8.6 \mathrm{~s}$. When the reaction was conducted at $C 0=10 \mathrm{mg} / \mathrm{L}$ and the residence time was reduced to $5.8 \mathrm{~s}$, a decolorization rate of $-r A=\sim 0.35 \mathrm{~g} / \mathrm{m}^{3} / \mathrm{s}$ was observed. Thus, there is a significant influence of external mass transfer resistance on the kinetics evaluated.

In the microreactor containing $\mathrm{TiO} 2-\mathrm{GR}$ immobilized on its inner walls submitted to $C 0=10 \mathrm{mg} / \mathrm{L}$ and $\tau=8.6 \mathrm{~s}$, the decolorization rate of methylene blue was $-r A=\sim 0.278 \mathrm{~g} / \mathrm{m}^{3} / \mathrm{s}$ at the steady-state. Additionally, a decolorization rate of $-r A=\sim 0.109 \mathrm{~g} / \mathrm{m}^{3} / \mathrm{s}$ was obtained for $C 0=1 \mathrm{mg} / \mathrm{L}$ and residence time of $8.6 \mathrm{~s}$ at the steady-state. Table 1 presents a summary of the reaction rates observed (for $\mathrm{TiO} 2$ and $\mathrm{TiO} 2-\mathrm{GR}$ ).

Therefore, there was no significant difference between the microreactors containing $\mathrm{TiO}_{2}$ and $\mathrm{TiO} 2-\mathrm{GR}$ immobilized on their inner walls in terms of reaction rates at the steady-state. However, a higher initial reaction rate was observed in the microreactor containing TiO2-GR, particularly for $C 0=10 \mathrm{mg} / \mathrm{L}$. Additionally, it should be emphasized that the film of $\mathrm{TiO} 2$ tended to be more stable compared with the reactor containing TiO2-GR since in the former the photocatalyst was 
deposited at a high-temperature $\left(450^{\circ} \mathrm{C}\right)$ that allowed the sintering of the material on the walls of the microfluidic chip. This temperature could not be applied for the thermal annealing of the TiO2-GR photocatalyst since it would certainly promote severe damage to the carbon structure of the graphene and, thus, modify its chemical identity. The temperature used for the thermal treatment of the microreactor containing $\mathrm{TiO} 2-\mathrm{GR}\left(150^{\circ} \mathrm{C}\right)$ probably did not promote a tight adhesion of the photocatalyst film on the walls of the microchannels, contributing to further deactivation due to the flow shear stress.

Furthermore, in the microreactor containing $\mathrm{TiO}_{2}$, the steady-state was reached after $80 \mathrm{~min}$ for $C 0=10 \mathrm{mg} / \mathrm{L}$ and $120 \mathrm{~min}$ for $C 0=1 \mathrm{mg} / \mathrm{L}$ after light was turned on. Conversely, the steadystate was obtained after $120 \mathrm{~min}$ for $C O=10 \mathrm{mg} / \mathrm{L}$ and $80 \mathrm{~min}$ for $C \theta=1 \mathrm{mg} / \mathrm{L}$ in the microreactor containing TiO2-GR. Thus, there was a distinct behavior between the two systems studied in terms of time interval needed to reach the steady-state. Interestingly, the opposite behavior was observed in terms of the initial methylene blue concentration.

Ling et al. ${ }^{27}$ studied the photocatalytic decolorization of methylene blue in a tubular reactor ( $I D=1.3 \mathrm{~cm}, L=25 \mathrm{~cm}, 10$ pieces) containing $\mathrm{TiO} 2$ immobilized on its inner walls. When operating at the temperature of $30^{\circ} \mathrm{C}, \mathrm{pH}$ of 6.9 , catalyst mass of $0.25 \mathrm{~g}$, air bubbling of $2.5 \mathrm{~cm}^{3} / \mathrm{s}$ and initial methylene blue concentration of $C_{0}=40 \mu \mathrm{M}(\sim 15 \mathrm{mg} / \mathrm{L})$, a reaction rate of $-r_{A}=$ $0.004 \mathrm{~g} / \mathrm{m}^{3} / \mathrm{s}$ was achieved. Reaction rates $\sim 50 \mathrm{x}$ and $\sim 90 \mathrm{x}$ higher were observed in our experiments when operating the microreactor containing $\mathrm{TiO} 2$ nanoparticles immobilized on the inner walls $\left(C O=10 \mathrm{mg} / \mathrm{L} ; \quad \tau=8.6 \mathrm{~s}\right.$ and $\tau=5.8 \mathrm{~s}$, respectively). Ling et al. ${ }^{27}$ worked with an aerated medium, which naturally enhances the photocatalytic activity, a condition that was not used in our experiments. Therefore, the advantage of the use of microreactors for the intensification of pollutant abatement reactions was demonstrated, because it can reach higher reaction rates compared with conventional equipment.

A maximum apparent first-order reaction constant of $k a p p=0.17 \mathrm{~s}^{-1}$ was obtained when operating with $C O=1 \mathrm{mg} / \mathrm{L}, \tau=8.6 \mathrm{~s}$ and $\mathrm{TiO} 2$ immobilized on the reactor walls. When TiO2-GR was considered, kapp, $\max =0.22 \mathrm{~s}^{-1}$ under the same operational conditions. These values are slightly lower than the apparent first-order reaction rate constant reported by Visan et al. $(2014)^{31}\left(k a p p=0.3 \mathrm{~s}^{-1}\right)$. Moreover, the values of kapp obtained in this study are considerably lower than the intrinsic value $\left(k=40 \mathrm{~s}^{-1}\right) .31$

\section{Computational modeling}

Figure 7 presents the results obtained from the computational simulations according the workflow discussed in previously. Particularly, Figure 7a shows the light intensity distribution in a cross section of the channel considering the walls covered with a $\mathrm{TiO} 2$ film with the same average thick- ness obtained experimentally.

It is possible to observe that considerably distinct average light intensities were obtained in each of the films layers. At the top of the microchannel, where the photocatalyst film was directly exposed to UV irradiation through a back-side illumination mechanism, ${ }^{32}$ the average light intensity was $I$ avg $=2.327 \mathrm{~W} / \mathrm{m}^{2}$. Conversely, at the side and bottom photo- catalyst layers, subjected to a front-side illumination mechanism, ${ }^{32}$ the average light intensities were $I_{a v g}=4.273310^{-1} \mathrm{~W} / \mathrm{m}^{2}$ and $I_{a v g}=7.536310^{-1} \mathrm{~W} / \mathrm{m}^{2}$, respectively.

Additionally, it should be stressed that the effect of internal mass transfer within all photocatalyst layers can be neglected, because the average effectiveness factor was close to the unity in all scenarios: $\eta=9.987 \times 10^{-1}, \eta=9.996 \times 10^{-1}$ and $\eta=9.998 \times 10^{-1}$ for the top, side 
and bottom layers, respectively. These results indicate that the entire film was exposed to approximately the same reaction conditions obtained at the catalyst surface.

Figure $7 \mathrm{~b}$ highlights the light intensity profile obtained through a line that crosses the channel cross section vertically at the center. One can notice that the higher light absorption occurs at the top layer of photocatalyst film, when $I$ decreases from $3.6 \mathrm{~W} / \mathrm{m}^{2}$ to approximately $1.4 \mathrm{~W} / \mathrm{m}^{2}$. In addition, light intensity was attenuated from $\sim 1.4$ to $\sim 0.5 \mathrm{~W} / \mathrm{m}^{2}$ within the bottom layer.

Finally, a computational study was carried out in the 3-D domain representing all features of the experimental setup, as described before. Figure $7 \mathrm{c}$ presents the results obtained. In particular, it should be highlighted that the methylene blue degradation equilibrium obtained numerically was significantly close to the experimental result ( $\sim 3 \%$ deviation was observed). Therefore, the computational model was validated and can be used for further investigations aiming to the scaleout of the photocatalytic abatement of pollutants in microfluidic systems, following numberingup strategies 9 as reported elsewhere. ${ }^{42,43}$

\section{Conclusions}

We have demonstrated the feasibility of using microfluidics for environmental applications in a $133.5 \mu \mathrm{m}$ internal hydraulic diameter borosilicate glass commercial microfluidic chip. $\mathrm{TiO} 2$ and composite catalyst of $\mathrm{TiO} 2$ and graphene ( $\mathrm{TiO} 2-\mathrm{GR})$ were used as photocatalysts and were deposited on the inner walls of the microchip using the optical profile evolution as a criterion. A kinetic study using methylene blue as model pollutant was carried out for the evaluation of the system performance. Although TiO2-GR allowed a higher initial reaction rate, the decolorization level was similar for both photocatalysts at the steady-state. Mass transfer limitation was found in our system. The observed reaction rate was at least one order of magnitude higher than that observed in reactors with conventional dimensions reported in the literature. This evidenced the potential use of microfluidic systems for process intensification. Recognized features of microchannel-based devices such as high area/surface ratio, fast mixing and short diffusive and photonic path contributed to the observed behavior. Furthermore, a rigorous computational model was implemented and validated with experimental data. This model will be used for further scaleout studies based on internal numbering-up strategies.

\section{Acknowledgments}

The authors would like to thank CAPES/Brazil (Project 347/13) and FCT/Portugal (Project 2649/12/3/2013) for financial support within cooperation project "Development and characterization of titanium oxide-graphene composites".

Padoin acknowledges CNPq (process number 140521/2014-3) for the scholarship in Brazil. C. Soares acknowledges CNPq for funding within project number 459299/2014-0. J. Ângelo is grateful to FCT for her PhD Grant

(Reference: SFRH/BD/79974/2011). L. Andrade and A. Mendes acknowledge European Research Council for funding within project BI-DSC - Building Integrated Dye sensitized Solar Cells (Contract Number: 321315). Research supported by LCME-UFSC (acquisition of SEM images).

\section{Notation}

$\alpha=$ optical absorption coefficient, $\mathrm{m}^{-1}$

$\delta=$ film thickness, $\mathrm{m}$

$\varepsilon=$ film porosity, dimensionless

$\phi=$ Thiele modulus, dimensionless

$\gamma=$ electron transfer coefficient, dimensionless 
$\lambda=$ wavelength, $\mathrm{nm}$

$\boldsymbol{\mu}=$ dynamic viscosity, $\mathrm{kg} / \mathrm{m} / \mathrm{s}$

$\eta=$ effectiveness factor, dimensionless

$\rho=$ density, $\mathrm{kg} / \mathrm{m}^{3}$

$\tau=$ residence time, $\mathrm{s}$

$\tau^{`}=$ catalyst tortuosity, dimensionless

$A=$ absorbance, dimensionless

BpOnO $=$ electron/hole recombination equilibrium, $\mathrm{m}^{3} / \mathrm{s}$

$C=$ methylene blue concentration, $\mathrm{mg} / \mathrm{L}$

$C O=$ initial methylene blue concentration, $\mathrm{mg} / \mathrm{L}$

$D=$ diffusion coefficient, $\mathrm{m}^{2} / \mathrm{s}$

Deff $=$ effective diffusion coefficient, $\mathrm{m}^{2} / \mathrm{s}$

$F=$ body forces, $\mathrm{N} / \mathrm{m}^{3}$

$h w=$ photon energy, $\mathrm{J}$

$I=$ identity matrix, dimensionless

$I=$ irradiance, $\mathrm{W} / \mathrm{m}^{2}$

$I 0=$ incident light intensity, $\mathrm{W} / \mathrm{m}^{2}$

$I^{e f f}=$ effective incident light intensity, $\mathrm{W} / \mathrm{m}^{2}$

$I_{\text {avg }}=$ average light intensity, $\mathrm{W} / \mathrm{m}^{2}$

$i=$ species, dimensionless

$I D=$ internal diameter, $\mathrm{m}$

$k=$ volumetric reaction rate constant, $\mathrm{s}^{-1}$

$k a p p=$ apparent first-order volumetric reaction rate constant, $\mathrm{s}^{-1}$

$k$ " app = apparent first-order superficial reaction rate constant, $\mathrm{m} / \mathrm{s}$

$L=$ length, $\mathrm{m}$

$L D=$ light dependent

$R=$ volumetric reaction rate, $\mathrm{mol} / \mathrm{m}^{3} / \mathrm{s}$

$-r A=$ reaction rate, $\mathrm{g} / \mathrm{m}^{3} / \mathrm{s}$

$p=$ pressure, $\mathrm{Pa}$

$t=$ time, $\mathrm{s}$

$T=$ transmittance, dimensionless

$T^{\prime}=$ transpose operator, dimensionless

$u=$ velocity vector, $\mathrm{m} / \mathrm{s}$

$y, x=$ Cartesian coordinates, $\mathrm{m}$

\section{Literature Cited}

1. Lam KF, Sorensen E, Gavriilidis A. Review on gas-liquid separations in microchannel devices. Chem Eng Res Des. 2013;91:1941- 1953.

2. Kenig EY, Su Y, Lautenschleger A, Chasanis P, Grenewald M. Microseparation of fluid systems: a state-of-the-art review. Sep Purif Technol. 2013;120:245-264.

3. Mills PL, Quiram DJ, Ryley JF. Microreactor technology and process miniaturization for catalytic reactions - a perspective on recent developments and emerging technologies. Chem Eng Sci. 2007;62: 6992-7010. 
4. Gavriilidis A, Angeli P, Cao E, Yeong KK, Wan YSS. Technology and applications of microengineered reactors. Chem Eng Res Des. 2002;80:3-30.

5. Jahnisch K, Hessel V, Lowe H, Baerns M. Chemistry in microstructured reactors. Angew Chem Int Ed. 2004;43:406-446.

6. Aran HC, Salamon D, Rijnaarts T, Mul G, Wessling M, Lammertink RGH. Porous photocatalytic membrane microreactor (P2M2): a new reactor concept for photochemistry. J Photochem Photobiol A: Chem. 2011;225:36-41.

7. Hartman RL, McMullen JP, Jensen KF. Deciding whether to go with the flow: evaluating the merits of flow reactors for synthesis. Angew Chem Int Ed. 2011;50:7502-7519.

8. Noel T, Su Y, Hessel V. Beyond organometallic flow chemistry: the principles behind the use of continuous-flow reactors for synthesis. Berlin, Heidelberg: Springer Berlin Heidelberg, 2015:1-41.

9. Su Y, Straathof NJW, Hessel V, Noel T. Photochemical transformations accelerated in continuous-flow reactors: basic concepts and applications. Chem - A Eur J. 2014;20:10562-10589.

10. Su Y, Talla A, Hessel V, Noel T. Controlled photocatalytic aerobic oxidation of thiols to disulfides in an energy-efficient photomicror- eactor. Chem Eng Technol. 2015;38:1733-1742.

11. Su Y, Hessel V, Noel T. A compact photomicroreactor design for kinetic studies of gas-liquid photocatalytic transformations. AIChE J. 2015;61:22152227.

12. Matsushita Y, Ohba N, Kumada S, Sakeda K, Suzuki T, Ichimura T. Photocatalytic reactions in microreactors. Chem Eng J. 2008;135: S303-S308.

13. Gorges R, Meyer S, Kreisel G. Photocatalysis in microreactors. $J$ Photochem Photobiol A: Chem. 2004;167:95-99.

14. Van Gerven T, Mul G, Moulijn J, Stankiewicz A. A review of inten- sification of photocatalytic processes. Chem Eng Process: Process Intensif. 2007;46:781789.

15. Coyle EE, Oelgemoller M. Micro-photochemistry: photochemistry in microstructured reactors. The new photochemistry of the future? Photochem Photobiol Sci. 2008;7:1313-1322.

16. Charles G, Roques-Carmes T, Becheikh N, Falk L, Commenge J-M, Corbel S. Determination of kinetic constants of a photocatalytic reaction in micro-channel reactors in the presence of mass-transfer limitation and axial dispersion. $J$ Photochem Photobiol A: Chem. 2011;223:202-211.

17. Dean RN, Surgnier S, Pack J, et al. Porous ceramic packaging for a MEMS humidity sensor requiring environmental access. IEEE Trans Comp Pack Manuf Technol. 2011;1:428-435.

18. Charles G, Roques-Carmes T, Becheikh N, Falk L, Corbel S. Impact of the design and the materials of rectangular microchannel reactors on the photocatalytic decomposition of organic pollutant. Green Pro- cess Synth. 2012;1:363.

19. Corbel S, Becheikh N, Roques-Carmes T, Zahraa O. Mass transfer measurements and modeling in a microchannel photocatalytic reac- tor. Chem Eng Res Des. 2014;92:657-662.

20. Zhang H, Lv X, Li Y, Wang Y, Li J. P25-graphene composite as a high performance photocatalyst. ACS Nano. 2009;4:380-386.

21. Offeman R, Hummers W. Preparation of graphitic oxide. $J$ Am Chem Soc. 1958;80:1339-1339. 
22. Zhang H, Lv X, Li Y, Wang Y, Li J. P25-Graphene composite as a high performance photocatalyst. ACS Nano. 2010;4:380-386.

23. Ramos B, Ookawara S, Matsushita Y, Yoshikawa S. Low-cost poly- meric photocatalytic microreactors: catalyst deposition and perform- ance for phenol degradation. J Environ Chem Eng. 2014;2:1487-1494.

24. Reis NM, Li Puma G. A novel microfluidic approach for extremely fast and efficient photochemical transformations in fluoropolymer microcapillary films. Chem Commun. 2015;51:8414-8417.

25. Hummers WS, Offeman RE. Preparation of graphitic oxide. J Am Chem Soc. 1958;80:1339-1339.

26. Magalhães P, A ngelo J, Sousa VM, Nunes OC, Andrade L, Mendes Synthesis and assessment of a graphene-based composite photoca- talyst. Biochem Eng J. 2015;104:20-26.

27. Ling CM, Mohamed AR, Bhatia S. Performance of photocatalytic reactors using immobilized $\mathrm{TiO}_{2}$ film for the degradation of phenol and methylene blue dye present in water stream. Chemosphere.2004;57:547-554.

28. Wu C-H, Chern J-M. Kinetics of photocatalytic decomposition of methylene blue. Ind Eng Chem Res. 2006;45:6450-6457.

29. McCullagh C, Robertson PKJ, Adams M, Pollard PM, Mohammed Development of a slurry continuous flow reactor for photocata- lytic treatment of industrial waste water. J Photochem Photobiol A: Chem. 2010;211:42-46.

30. Nielsen MG, In S-I, Vesborg PCK, T Pedersena, KP Almtoftc, IH Andersenc, O Hansena, Ib Chorkendor. A generic model for photo- catalytic activity as a function of catalyst thickness. J Catal. 2012; 289:62-72.

31. Visan A, Rafieian D, Ogieglo W, Lammertink RGH. Modeling intrinsic kinetics in immobilized photocatalytic microreactors. Appl Catal B: Environ. 2014;150151:93-100.

32. Chen D, Li F, Ray AK. External and internal mass transfer effect on photocatalytic degradation. Catal Today. 2001;66:475-485.

33. Milo ič N, Lubej M, Novak U, nidar ič-Plazl P, Plazl I. Evaluation of diffusion coefficient determination using a microfluidic device. Chem Biochem Eng Q. 2014;28:215-223.

34. Ould-Mame S, Zahraa O, Bouchy M. Photocatalytic degradation of salicylic acid on fixed TiO2-kinetic studies. Int J Photoenerg. 2000; 2:59-66.

35. Boyjoo Y, Ang M, Pareek V. Some aspects of photocatalytic reactor modeling using computational fluid dynamics. Chem Eng Sci. 2013; 101:764-784.

36. Kim K, Kim M-J, Kim S-I, Jang J-H. Towards visible light hydro- gen generation: quantum dot-sensitization via efficient light harvest- ing of hybridTiO2. Sci Rep. 2013;3:1-8.

37. Choi W, Ko JY, Park H, Chung JS. Investigation on TiO2-coated optical fibers for gas-phase photocatalytic oxidation of acetone. Appl Catal B: Environ. 2001;31:209-220.

38. Williams G, Seger B, Kamat PV. TiO2-graphene nanocomposites. UV-assisted photocatalytic reduction of graphene oxide. ACS Nano. 2008;2:1487-1491.

39. Nguyen-Phan T-D, Pham VH, Shin EW, Pham H-D, Kim S, Chung JS, Kim EJ, Hur SH. The role of graphene oxide content on the adsorption-enhanced photocatalysis of titanium dioxide/graphene oxide composites. Chem Eng J. 2011;170:226-232.

40. Wu F, Liu W, Qiu J, Li J, Zhou W, Fang Y, Zhang S, Li X. Enhanced 
photocatalytic degradation and adsorption of methylene blue via $\mathrm{TiO} 2$ nanocrystals supported on graphene-like bamboo char- coal. Appl Surf Sci. 2015;358, Part A:425-435.

41. Stefanov BI, Kaneva NV, Puma GL, Dushkin CD. Novel integrated reactor for evaluation of activity of supported photocatalytic thin films: case of methylene blue degradation on $\mathrm{TiO} 2$ and nickel modi- fied $\mathrm{TiO} 2$ under $\mathrm{UV}$ and visible light. Colloid Surf A: Physicochem Eng Asp. 2011;382:219-225.

42. Su Y, Kuijpers K, Hessel V, Noel T. A convenient numbering-up strategy for the scale-up of gas-liquid photoredox catalysis in flow. React Chem Eng. 2016;1:7381.

43. Russo D, Spasiano D, Vaccaro M, Andreozzi R, Puma GL, Reis NM, Marotta R. Direct photolysis of benzoylecgonine under UV irradiation at $254 \mathrm{~nm}$ in a continuous flow microcapillary array pho- toreactor. Chem Eng J. 2016;283:243-250.

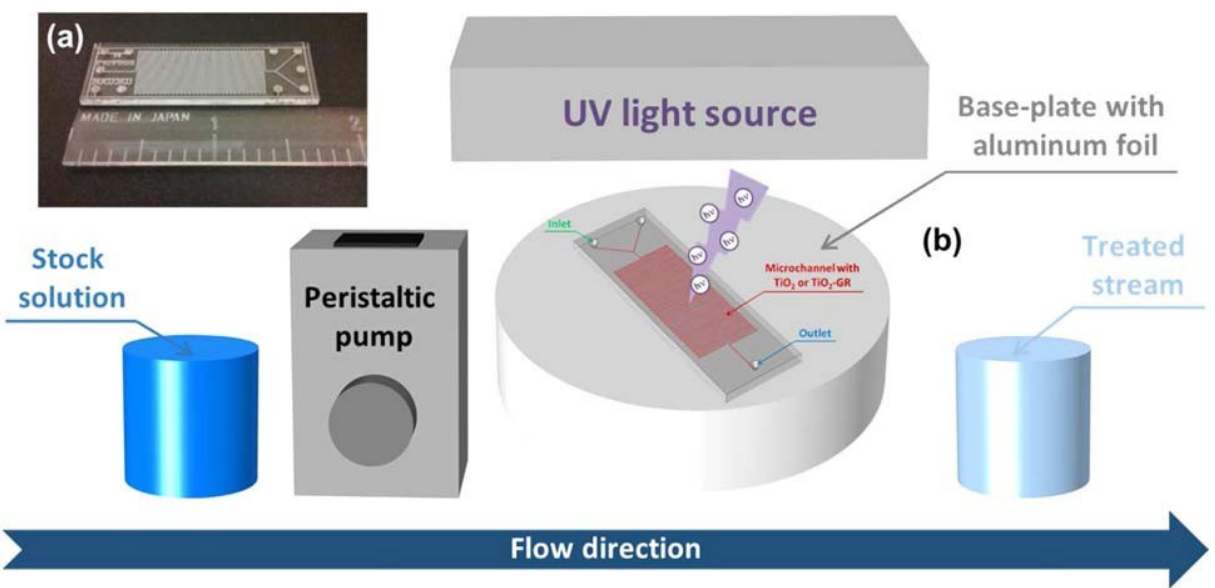

Figure 1. Experimental setup: (a) microfluidic chip at real scale; (b) sketch of the apparatus used for the investigation of methylene blue degradation kinetics

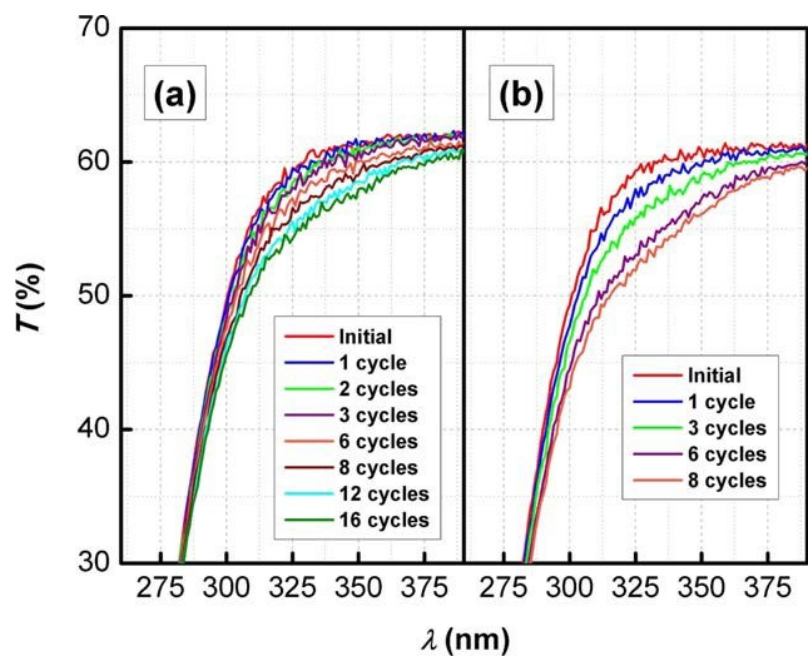

Figure 2. Transmittance profile evolution for (a) the microfluidic chip containing titanium dioxide nanoparticles $\left(\mathrm{TiO}_{2}-\mathrm{P} 25\right)$ and (b) composite catalyst of titanium dioxide and graphene $\left(\mathrm{TiO}_{2}-\mathrm{GR}\right)$ immobilized on its inner walls 

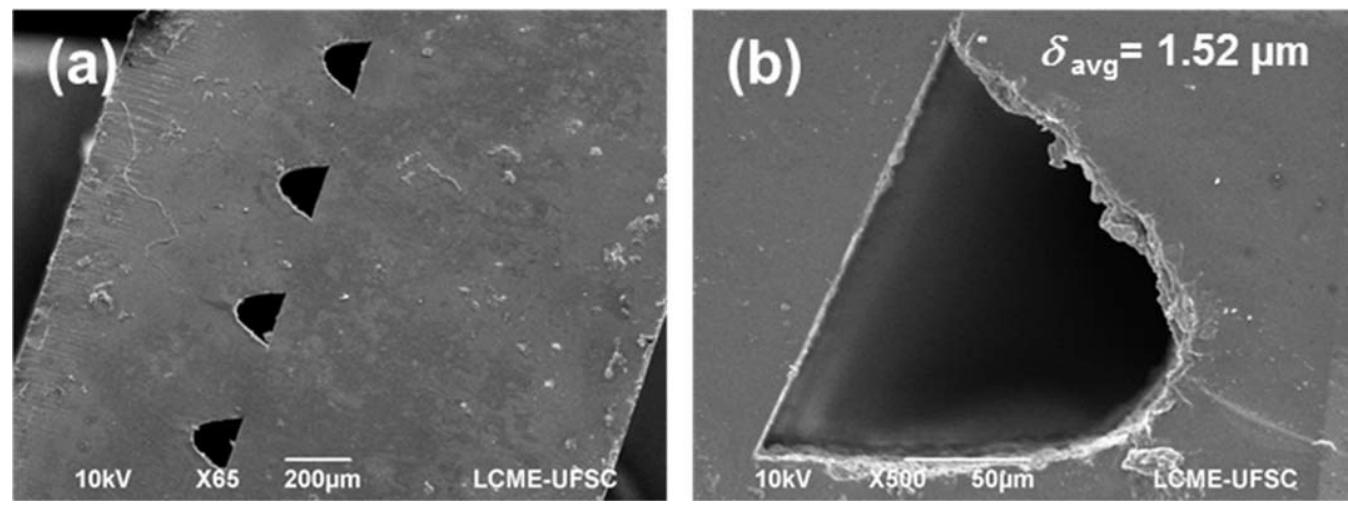

Figure 3. SEM images of a cross section of the microreactor obtained at the center of the device. Magnification is highlighted in the respective pictures.

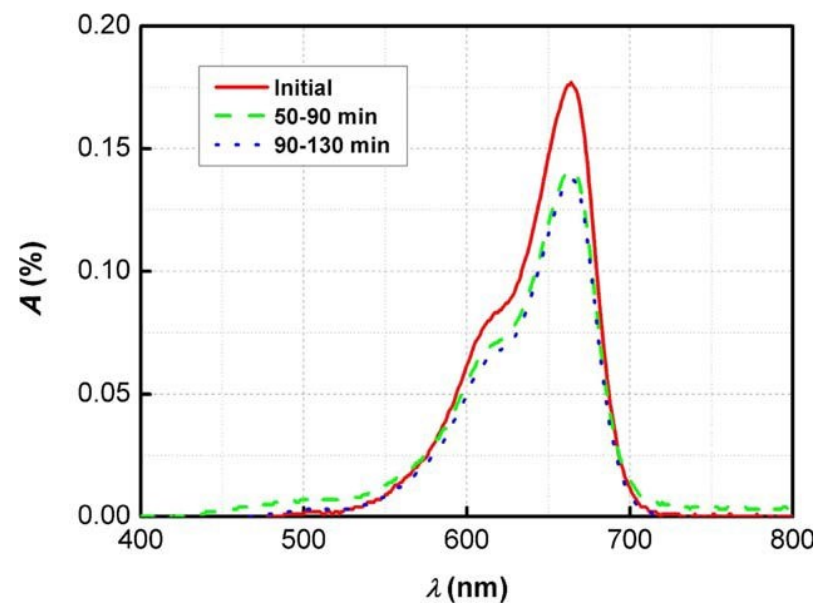

Figure 4. Absorption spectrum of the methylene blue dye in the preliminary study under dark conditions

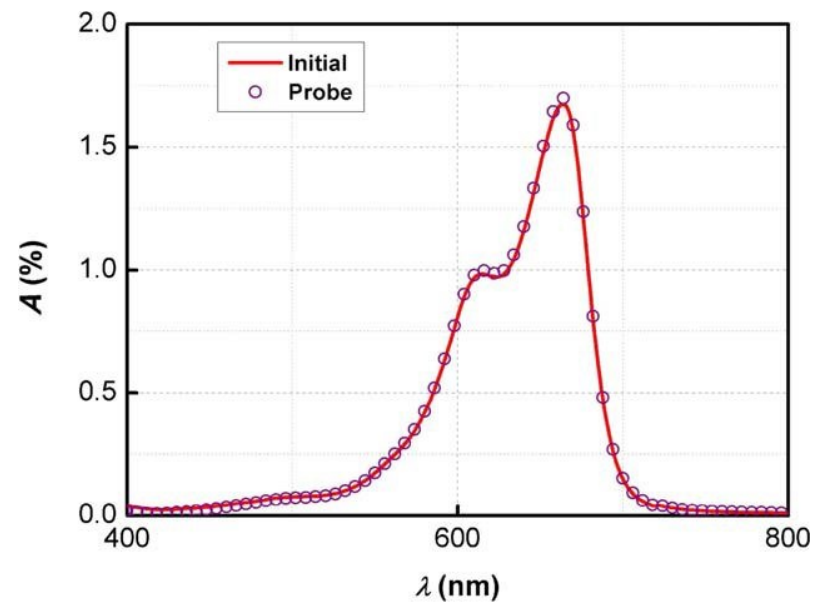

Figure 5. Absorption spectrum of the methylene blue dye in the preliminary study of photolysis effect on the performance of the system 

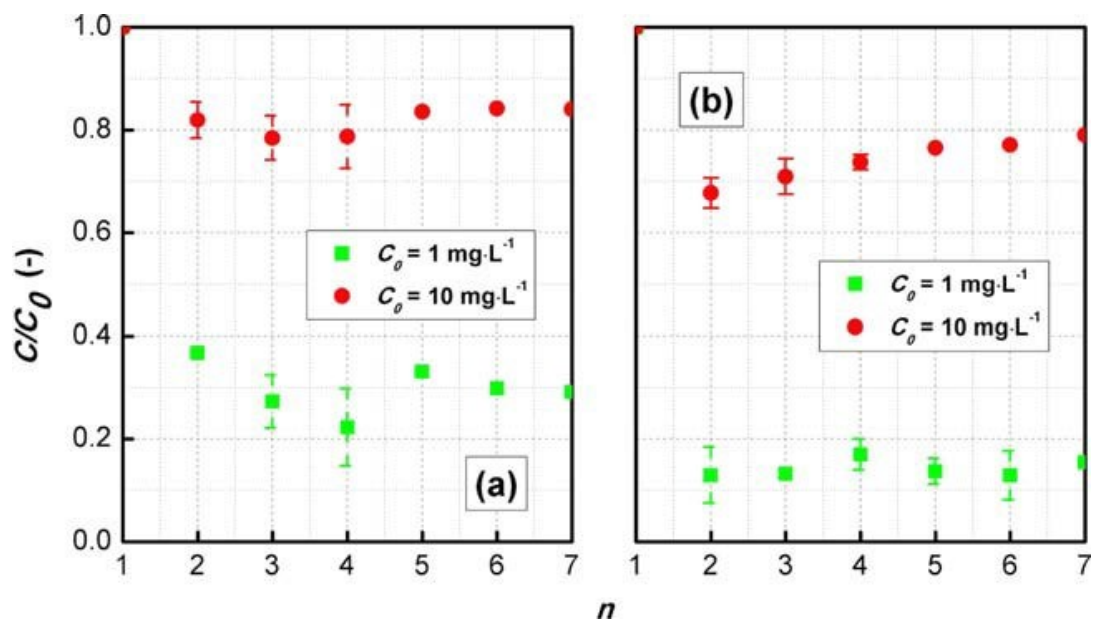

Figure 6. Decolorization profiles of methylene blue obtained with (a) the microfluidic chip containing titanium dioxide nanoparticles $\left(\mathrm{TiO}_{2} \mathrm{P} 25\right)$ immobilized on its inner walls and (b) the microfluidic chip containing composite catalyst of titanium dioxide and graphene $\left(\mathrm{TiO}_{2}-\mathrm{GR}\right)$ immobilized on its inner walls. The label $n$ represents the samples acquired
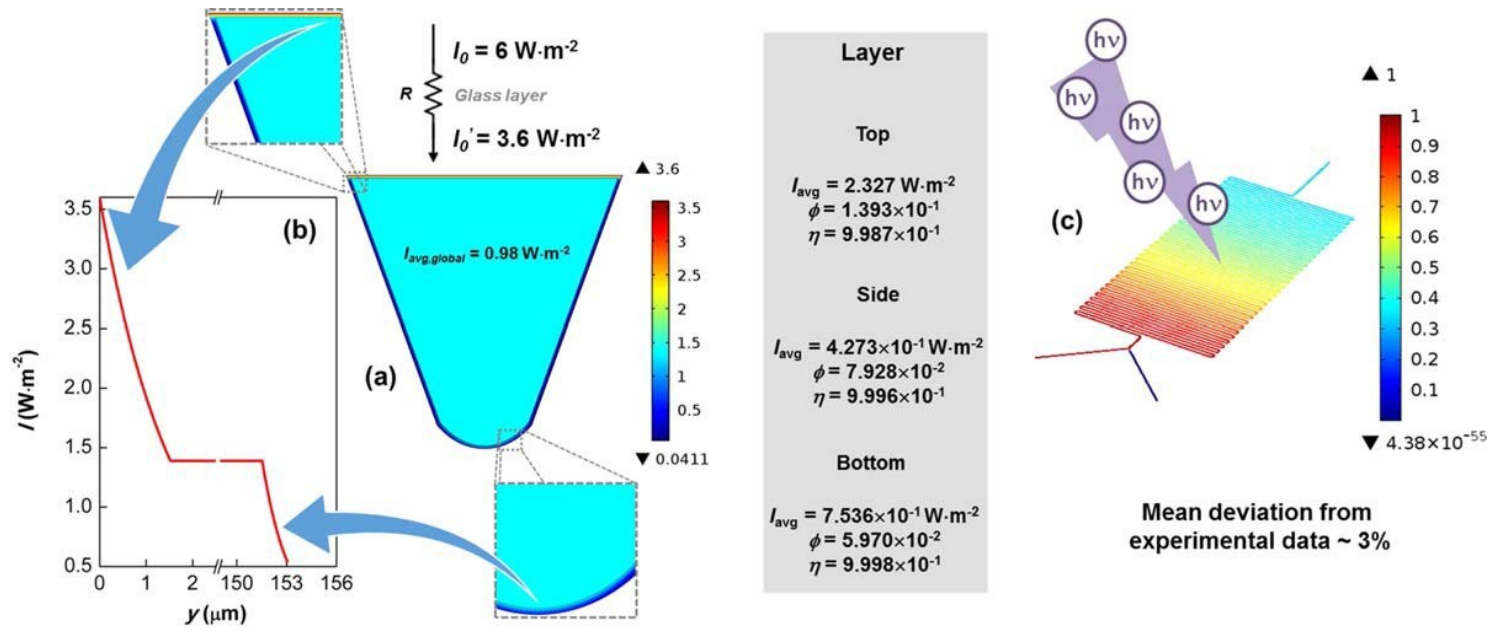

Mean deviation from experimental data $\sim 3 \%$

Figure 7. Computational model of methylene blue degradation in the microchannel containing titanium dioxide nanoparticles $\left(\mathrm{TiO}_{2}-\mathrm{P} 25\right)$ immobilized on its inner walls: (a) light distribution at the photocatalyst layers (top, side, and bottom); (b) light intensity profile in a vertical line crossing the center of the computational domain; (c) degradation profile obtained at the steady-state $\left(C_{0} 51 \mathrm{mg} / \mathrm{L}\right.$ and $\left.\mathrm{s} 58.6 \mathrm{~s}\right)$ in the 3-D geometry. Details about average light intensity, Thiele modulus and effectiveness factor at each film layer are also presented

Table 1. Summary of the Experimental Conditions Adopted in This Study and the Respective Reaction Rates Observed

\begin{tabular}{lcccc}
\hline Photocatalyst & $C_{O M B}(\mathrm{mg} / \mathrm{L})$ & $\tau(\mathrm{s})$ & $I_{0}\left(\mathrm{~W} / \mathrm{m}^{2}\right)$ & $-r_{A}\left(\mathrm{~g} / \mathrm{m}^{3} / \mathrm{s}\right)$ \\
\hline $\mathrm{TiO}_{2}$ & 1 & 8.6 & & 0.0988 \\
& 10 & 5.8 & 6 & 0.209 \\
$\mathrm{TiO}_{2}-\mathrm{GR}$ & 1 & 8.6 & & 0.35 \\
& 10 & & & 0.109 \\
& & & & 0.278 \\
\hline
\end{tabular}

